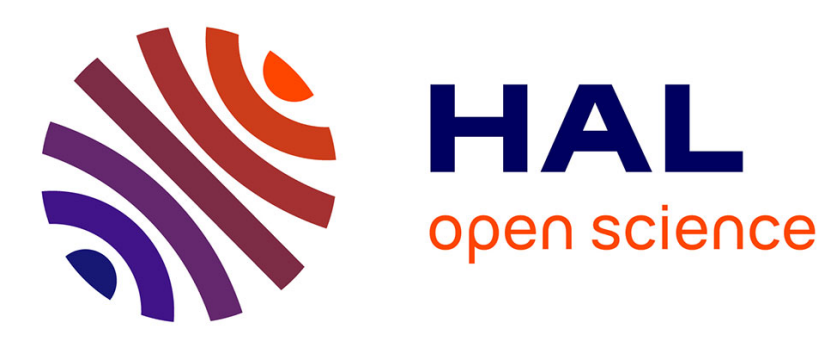

\title{
Highly Cooperative Formation of Bis-Urea Based Supramolecular Polymers
}

Vesna Simic, Laurent Bouteiller, Matthieu Jalabert

\section{To cite this version:}

Vesna Simic, Laurent Bouteiller, Matthieu Jalabert. Highly Cooperative Formation of Bis-Urea Based Supramolecular Polymers. Journal of the American Chemical Society, 2003, 125 (43), pp.13148-13154. $10.1021 / \mathrm{ja037589x}$. hal-01696750

\section{HAL Id: hal-01696750 https://hal.science/hal-01696750}

Submitted on 29 Aug 2020

HAL is a multi-disciplinary open access archive for the deposit and dissemination of scientific research documents, whether they are published or not. The documents may come from teaching and research institutions in France or abroad, or from public or private research centers.
L'archive ouverte pluridisciplinaire HAL, est destinée au dépôt et à la diffusion de documents scientifiques de niveau recherche, publiés ou non, émanant des établissements d'enseignement et de recherche français ou étrangers, des laboratoires publics ou privés. 


\title{
Highly cooperative formation of bis-urea based supramolecular polymers
}

\author{
Vesna Simic, Laurent Bouteiller, Matthieu Jalabert
}

Laboratoire de Chimie des Polymères, UMR 7610, Université Pierre et Marie Curie, 4 place Jussieu, 75252 Paris cedex 05, France

\begin{abstract}
Eleven bis-ureas have been synthesized, and some of their properties are reported. Several of these compounds form supramolecular polymers in organic solvents. The selfassociation is shown by FTIR spectroscopy to display cooperativity at two levels. The first level of cooperativity is due to the synergistic association of the two urea functions of a single molecule. The second level of cooperativity is revealed by the fact that the formation of dimers is less favored than the formation of long oligomers.
\end{abstract}

\section{Introduction}

Supramolecular polymers are chains of small molecules held together through reversible noncovalent interactions. ${ }^{1.3}$ This reversibility is responsible for the appearance of new properties, as compared to those of usual covalent polymers. For instance, the molar mass dependence of supramolecular polymers on concentration, solvent polarity and temperature leads to unusual rheological properties, which are potentially useful for a wide range of applications. 
We have recently described a new supramolecular polymer (EHUT, see Chart 1), based on the bis-urea moiety. ${ }^{4}$ EHUT has been shown to form highly viscoelastic solutions in toluene, due to self-association through hydrogen bonding, leading to the formation of very long cylindrical

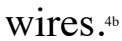

Interestingly, the properties of EHUT are quite different from similar bis-ureas described in the

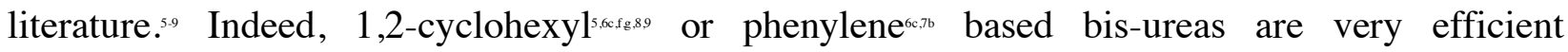
organogelators, ${ }^{10}$ meaning that after dissolution at high temperature, a gel is formed at room temperature due to solvent entrapment in a network of crystalline fibers. The main differences between these kinds of compounds are first the fact that, unlike organogelators, EHUT dissolves at room temperature, without any activation, in solvents where it forms a viscoelastic solution. Therefore, these solutions are thermodynamically stable. As a consequence, the length of the wires formed by EHUT can be altered by a slight change in experimental conditions, which is not the case for organogels below their melting point (once the gel is formed). Secondly, the cross-section of EHUT wires has been shown to be $2.6 \mathrm{~nm}$ in diameter, which corresponds to the largest dimension of the molecule, whereas the cross-sections of the fibers reported for organogelators are at least an order of magnitude larger. Consequently, the organogels display a much stronger elastic modulus than the viscoelastic solutions of EHUT.

Considering the singular properties of EHUT compared to bis-urea organogelators, we investigated the influence of small structural variations, to see if other supramolecular polymers could be obtained (see the second part of this paper). Characterization was performed by capillary viscometry to qualitatively reveal the high molar mass of the assemblies and by FTIR spectroscopy, because it is ideally suited to measure the degree of association of substituted ureas." The FTIR characterization of EHUT is described in the first part of this paper. 

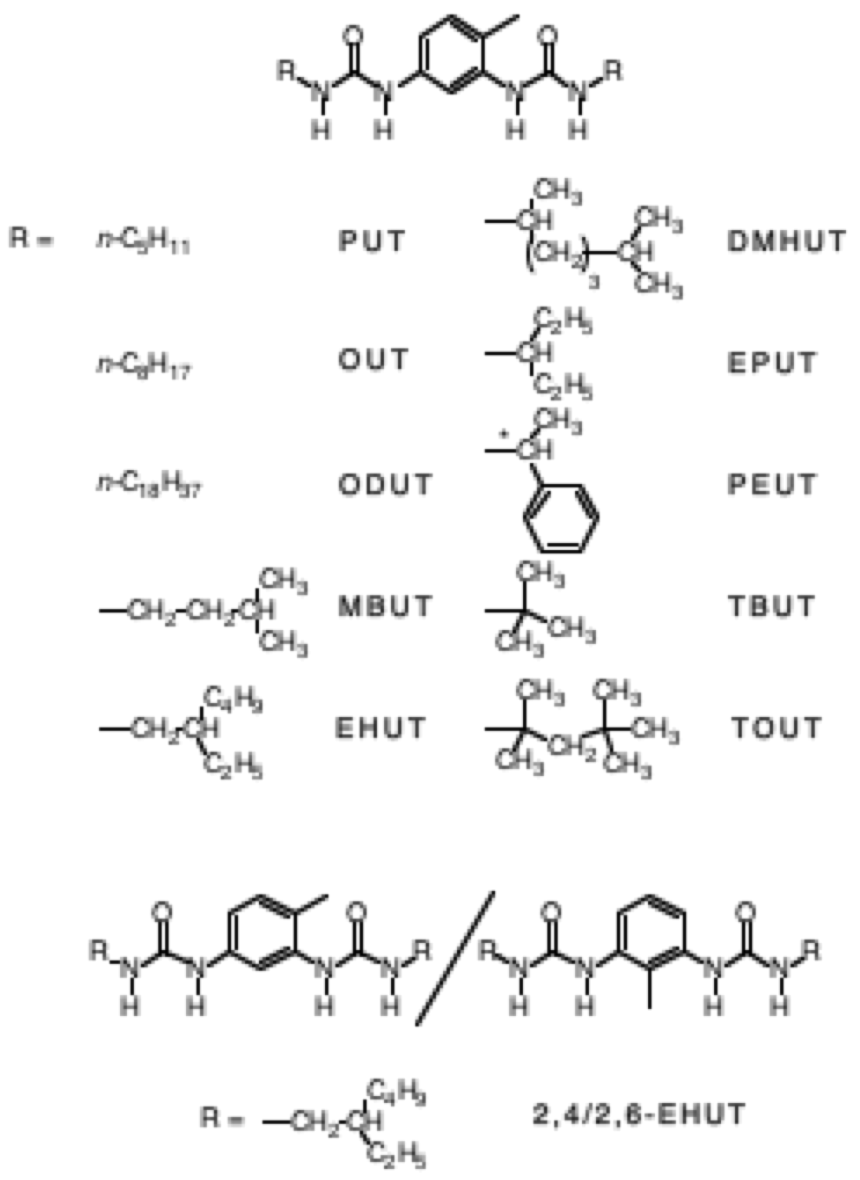

Chart 1. Structures of bis-ureas studied.

\section{Results and Discussion}

1 - Characterization of EHUT: Figure 1 qualitatively shows the influence of solvent on the formation of high molar mass supramolecular assemblies. The lower the polarity and the hydrogen bonding ability of the solvent, the higher the viscosity of the solutions of EHUT, due to stronger self-association by hydrogen bonding. 


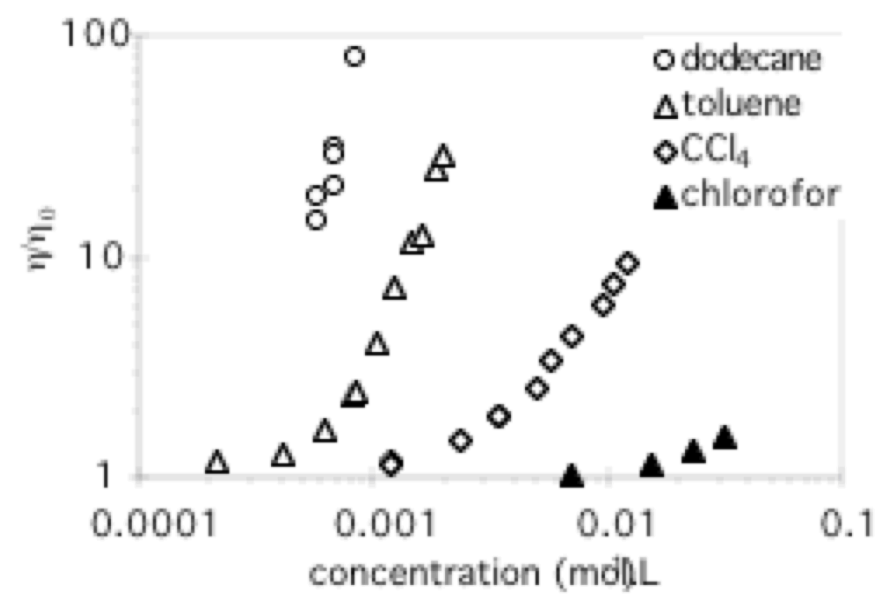

Figure 1. Relative viscosity of EHUT solutions in different solvents, at $25^{\circ} \mathrm{C}$.

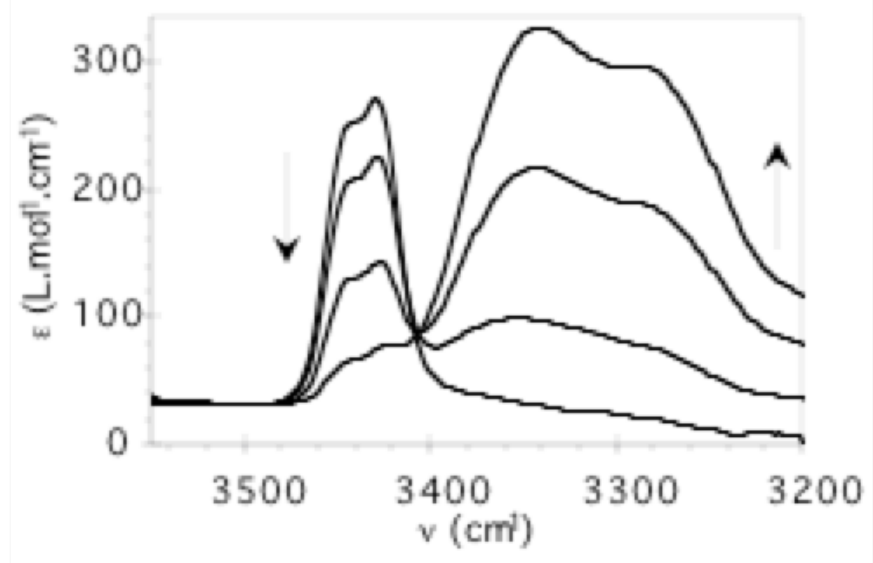

Figure 2. Normalized FTIR spectra of solutions of EHUT in $\mathrm{CDCl}_{3}$, versus concentration $(4.0 \mathrm{x}$ $10^{4}, 8.9 \times 10^{4}, 1.8 \times 10^{3}$ and $8.9 \times 10^{3}$ mol.L $\left.\mathrm{L}^{-1}\right)$. Arrows indicate the direction of change with increasing concentration.

It would be desirable to perform the spectroscopic characterization of the association in the solvents where the association is the strongest. Unfortunately FTIR spectra of solutions of EHUT in dodecane, toluene or carbon tetrachloride show only a hydrogen bonded N-H peak, down to 
the lowest concentration accessible. The intensity of the free $\mathrm{N}-\mathrm{H}$ vibration is too small to be detected, so that the quantitative characterization of any equilibrium is impossible by FTIR..$^{2}$ Chloroform, however presents a good compromise because the association of EHUT is here sufficiently disfavored to allow quantitative measurements, but still significant to be informative. $\mathrm{CDCl}_{3}$ was used instead of $\mathrm{CHCl}_{3}$, to minimize the solvent absorption in the $\mathrm{N}-\mathrm{H}$ stretching vibration region. Figure 2 shows FTIR spectra of solutions of EHUT at several concentrations in $\mathrm{CDCl}_{3}$. Four bands can be distinguished: the two bands at 3444 and $3429 \mathrm{~cm}^{-1}$ can be attributed to free N-H groups and the two bands at 3340 and $3280 \mathrm{~cm}^{-1}$ to hydrogen bonded N-H groups." This assignment is in agreement with an increase of molar mass of the assemblies with concentration (Figure 1), because the relative magnitude of the free $\mathrm{N}-\mathrm{H}$ vibration decreases with increasing concentration. Before analysing these curves more quantitatively, it is desirable to assign more precisely each vibration. Figure 3 compares the spectrum of EHUT to those of model monoureas (Chart 2).

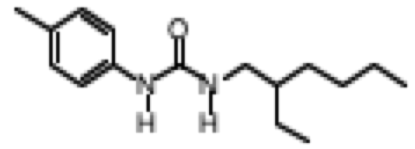

4T/EHU

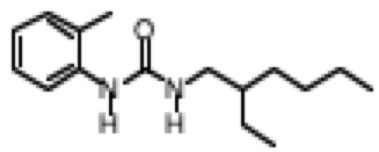

2T/EHU

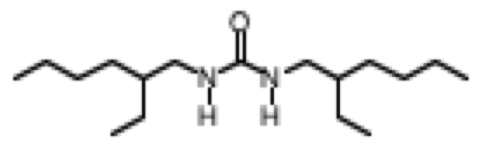

EHU

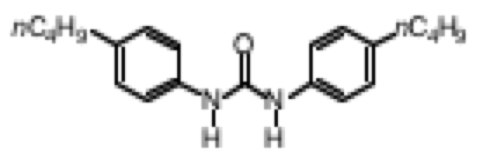

BPU

Chart 2. Structure of model mono-ureas studied. 

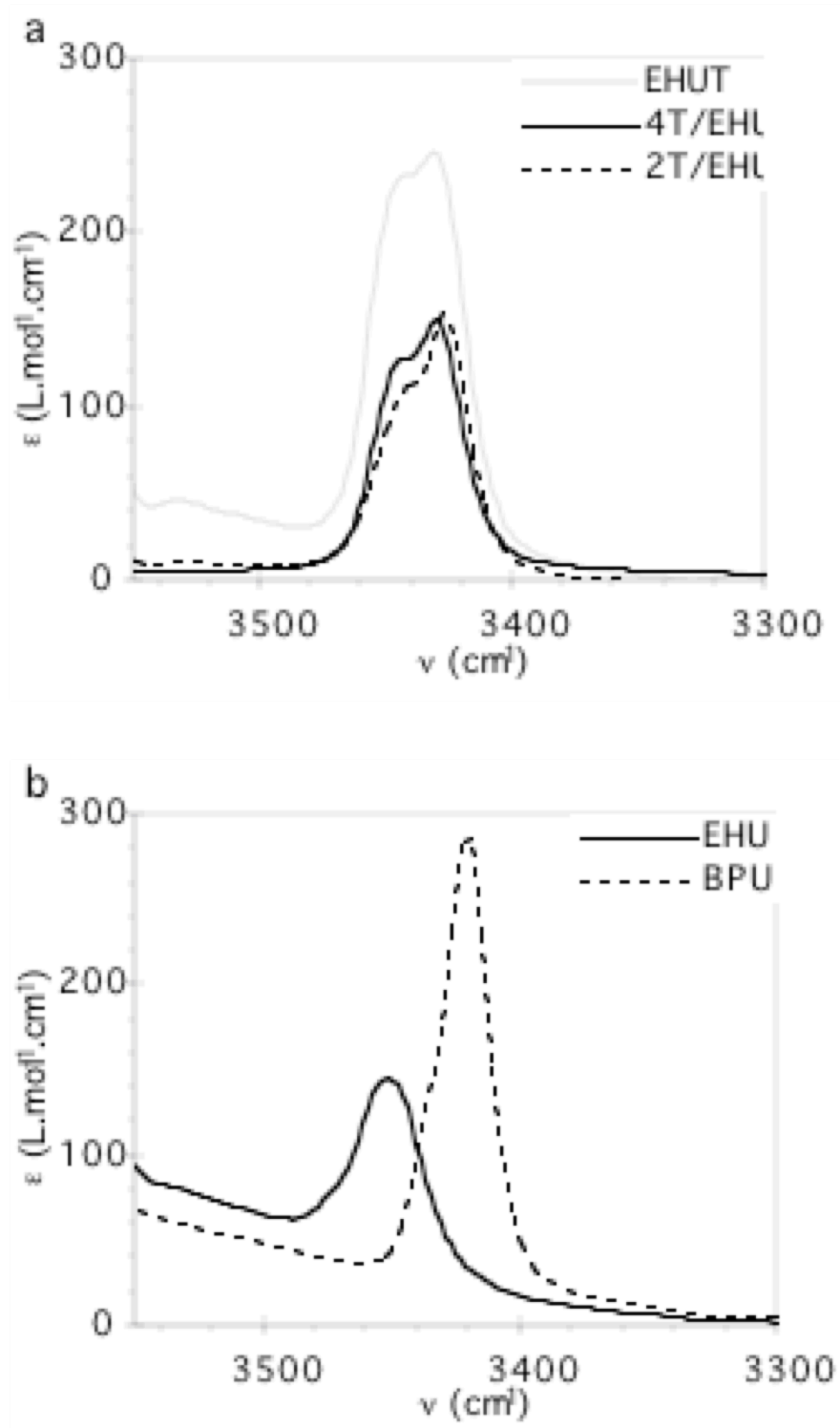

Figure 3. FTIR spectra of solutions of EHUT and model mono-ureas at a concentration of about $10^{-4} \mathrm{~mol}_{\mathrm{L}}^{-1}$, in $\mathrm{CDCl}_{3}$.

Symmetrical mono-ureas EHU and BPU were chosen as aliphatic and aromatic references, respectively, and $\mathbf{2 T} / \mathbf{E H U}$ and $\mathbf{4 T / E H U}$ were selected to assess the influence of the position of the methyl group. All the solutions considered in Figure 3 are sufficiently diluted, so that only the free $\mathrm{N}-\mathrm{H}$ vibrations are present. Comparison of the spectra of this figure affords the following 
assignment for EHUT: the band at $3444 \mathrm{~cm}^{-1}$ corresponds to the free aliphatic N-H group and the band at $3429 \mathrm{~cm}^{-1}$ corresponds to the free aromatic N-H group. No significant influence of the position of the methyl group on the aromatic bridging group is detected. A precise assignment of the hydrogen bonded $\mathrm{N}-\mathrm{H}$ vibrations is potentially more complicated, because the shift of the $\mathrm{N}$ $\mathrm{H}$ vibration due to self-association depends not only on the molecular structure, but also on the strength of the association and thus on the supramolecular structure, which is not the same for mono-ureas and EHUT. Proton/deuterium (H/D) exchange kinetics is a powerful technique used to derive information on hydrogen bonded systems. ${ }^{13}$ At time $\mathrm{t}=0, \mathrm{D}_{2} \mathrm{O}$ was added to a EHUT solution in chloroform, and the decrease of the N-H bands was monitored. Figure 4a shows that the intensity of the $3280 \mathrm{~cm}^{-1}$ vibration band decreases faster than the intensity of the $3340 \mathrm{~cm}^{-1}$ vibration band. Moreover, Figure $4 \mathrm{~b}$ shows that, for a 4T/EHU mono-urea solution, the free aromatic $\mathrm{N}-\mathrm{H}$ band $\left(3431 \mathrm{~cm}^{-1}\right)$ decreases faster than the free aliphatic $\mathrm{N}-\mathrm{H}$ band $\left(3446 \mathrm{~cm}^{-1}\right)$.

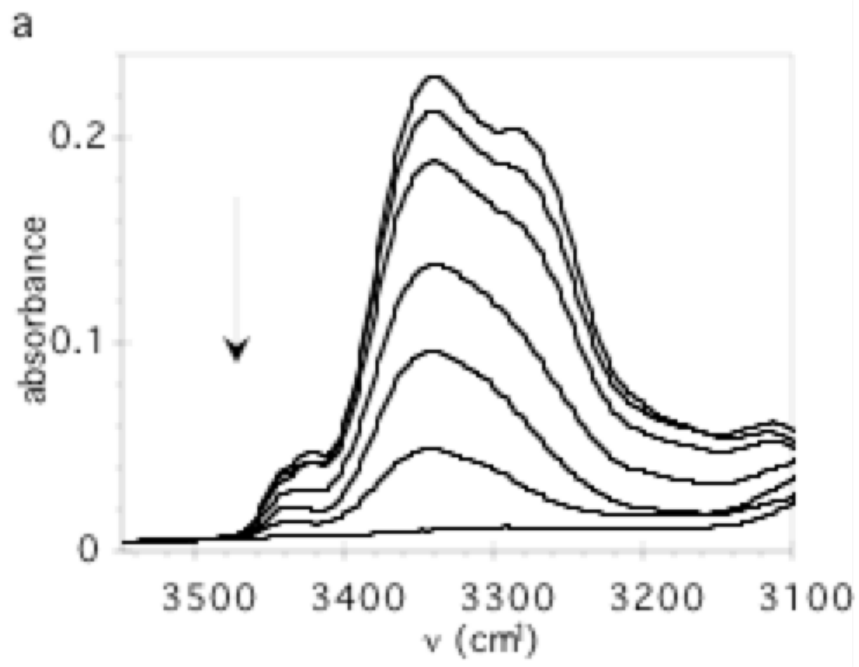




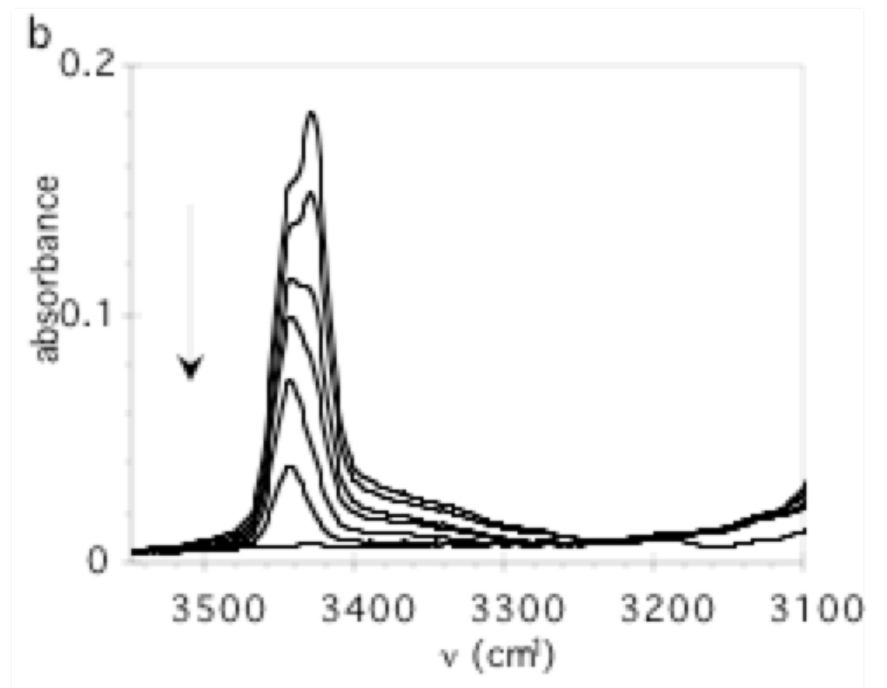

Figure 4. FTIR spectra of solutions of (a) bis-urea EHUT (7 x 10 $\left.0^{-3} \mathrm{~mol}^{-L^{-1}}\right)$ and (b) model monourea 4T/EHU $\left(11 \times 10^{-3}\right.$ mol. $\left.\mathrm{L}^{-1}\right)$ in $\mathrm{CDCl}_{3}$, versus time after addition of $\mathrm{D}_{2} \mathrm{O}$. Arrows indicate the direction of change with time. The half-life time is approximately 2 hours for (a) and 40 minutes for (b).

The present behavior of the mono-urea means that the stronger acidity of the aromatic $\mathrm{N}-\mathrm{H}$ group leads to an increase of the exchange dynamics. The same is to be expected for the bis-urea. Consequently, in the case of the bis-urea (Figure $4 \mathrm{a}$ ), the $3280 \mathrm{~cm}^{-1}$ band can be attributed to the hydrogen bonded aromatic group and the $3340 \mathrm{~cm}^{-1}$ band can be attributed to the hydrogen bonded aliphatic group of EHUT. This assignment has been confirmed by following the H/D exchange by 'H NMR in very similar conditions. Indeed, the two aromatic N-H resonances at (7.5 and $7.1 \mathrm{ppm})$ decrease at the same rate and faster than the two aliphatic $\mathrm{N}-\mathrm{H}$ resonances at $(6.1$ and $5.9 \mathrm{ppm})$.

A quantitative analysis of the spectra of Figure 2 was based on the measurement of the intensity of the free $\mathrm{N}-\mathrm{H}$ stretching vibrations, according to previous work on mono-ureas..$^{11.14}$ At very low concentration $\left(2.6 \times 10^{-4} \mathrm{~mol} . \mathrm{L}^{-1}\right)$, the spectrum of the totally dissociated bis-urea is 
obtained. This spectrum can then be used to determine the fraction of free $\mathrm{N}-\mathrm{H}$ groups in spectra of more concentrated solutions (see experimental section). The results are displayed on Figure 5, and compared to the results for solutions of model mono-ureas 4T/EHU and 2T/EHU.

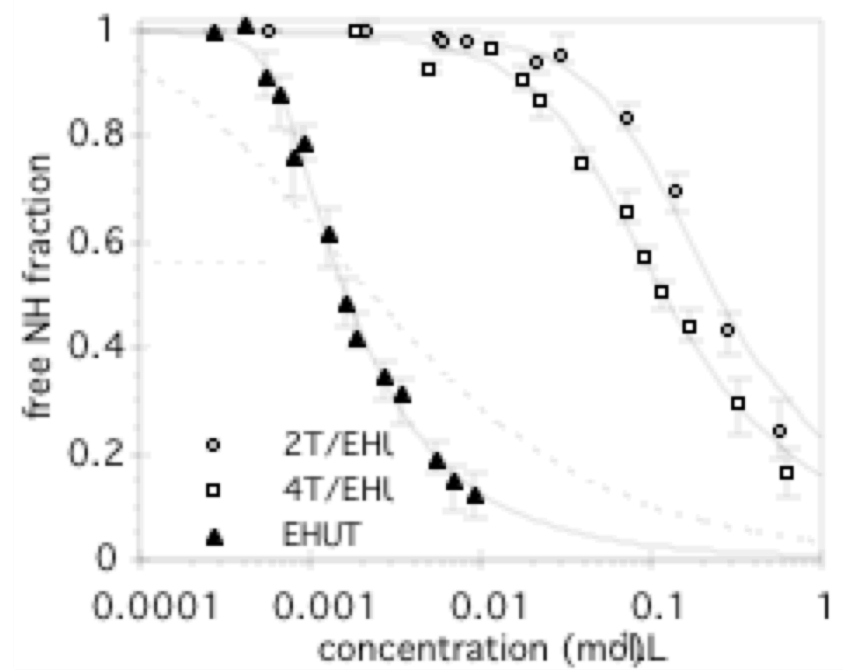

Figure 5. Fraction of free NH groups of bis-urea EHUT and model mono-ureas 4T/EHU and 2T/EHU, versus concentration in $\mathrm{CDCl}_{3}$, at room temperature. The full curves are calculated with the non-isodesmic model and the values of the constants reported in Table 1. The dotted curve is the best fit of the EHUT data with the isodesmic model.

This figure shows that the two model mono-ureas behave similarly, with 2 T/EHU being less associated than 4T/EHU, probably due to the steric hindrance of the methyl substituent. More importantly, this figure also proves that the association of bis-urea EHUT is more cooperative than the association of model mono-ureas at two levels. First of all, the curves for EHUT and for the mono-ureas are separated by 2 orders of magnitude on the concentration scale. If the two urea functions of bis-urea EHUT assembled independently from each other, we would only expect a separation of a factor 2 between the curves (because the concentration scale is in molecules and not in urea functions). Thus, the additional 50-fold shift proves that hydrogen bonding of the first 
urea function of a molecule of EHUT facilitates the association of the second urea function in the supramolecular assembly. Secondly, the decrease of the free $\mathrm{N}-\mathrm{H}$ fraction is steeper for EHUT than for mono-ureas. This means that the transition from monomer to long supramolecular polymers through the sequence of association equilibria (Scheme 1) is sharper for the bis-urea than for mono-ureas. In other words, the formation of short oligomers (dimers, trimers, ...) triggers the formation of long chains in the case of bis-urea. ${ }^{15}$ This is the manifestation of cooperativity at a second level.

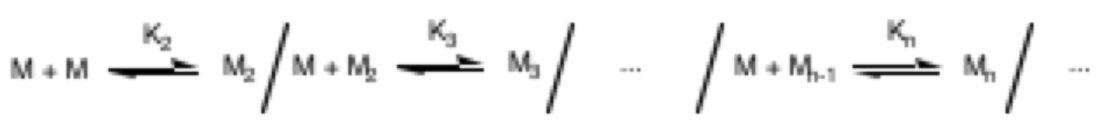

Scheme 1. Association equilibria involved in the formation of a supramolecular polymer $(\mathrm{M}=$ monomer, $\mathbf{M}_{\mathrm{n}}=$ oligomer of degree of polymerization $\mathrm{n}$ ).

These descriptions can be made more precise by fitting a particular model to the data of Figure 5. The simplest (isodesmic) model (i.e. $K_{n}=K$, for $n \geq 2$ ) ${ }^{16}$ does not yield a good description of the data, as already reported for mono-ureas, ${ }^{1,14}$ but the second simplest model $\left(K_{2} \neq K=K_{n}\right.$, for $n$ $\geq 3$ ) yields an excellent fit of all the data. The values of the constants derived are reported in Table 1. The value of $\mathrm{K} / \mathrm{K}_{2}$ is a measure of the second level of cooperativity (along the supramolecular chain). The fact that the association of mono-ureas is cooperative and can be described by the two constant model $\left(\mathrm{K}_{2}, \mathrm{~K}\right)$ has already been reported and attributed to polarization of the urea function subsequent to the formation of dimers." The $K / K_{2}$ value for bisurea EHUT shows that the association of EHUT is even more cooperative than the association of mono-ureas, as has been deduced from the shape of the curves. The reason for the higher 
cooperativity $\left(\mathrm{K} / \mathrm{K}_{2}\right)$ of the association of EHUT compared to mono-ureas is certainly related to significant differences in the respective molecular arrangements. For example, the bimolecular structure previously proposed for $\mathbf{E H U T}^{\mathrm{a}}$ is in agreement with such an observation. ${ }^{17}$

Table 1. Characteristics of solutions of mono and bis-ureas in $\mathrm{CDCl}_{3}$ at room temperature.

\begin{tabular}{|c|c|c|c|c|c|}
\hline & 2T/EHU & 4T/EHU & MBUT & EHUT & DMHUT \\
\hline $\mathbf{V}_{\mathrm{f}}^{\mathrm{N}-\mathrm{H} a}$ & 3444 / 3427 & $3446 / 3431$ & 3442 / 3431 & 3444 / 3429 & 3435 / 3427 \\
\hline$V_{\mathrm{b}^{\mathrm{N}}}^{\mathrm{N} a}$ & 3355 & 3350 & 3335 / 3290 & 3340 / 3280 & 3325 / 3280 \\
\hline $\mathrm{K}_{2}{ }^{b}$ & $1.8 \pm 0.5$ & $4.5 \pm 0.5$ & $7 \pm 4$ & $21 \pm 3$ & $14 \pm 7$ \\
\hline $\mathrm{K}^{b}$ & $8.0 \pm 1.0$ & $16.6 \pm 3.0$ & $2300 \pm 200$ & $1400 \pm 200$ & $1700 \pm 100$ \\
\hline $\mathrm{K} / \mathrm{K}_{2}{ }^{c}$ & $4.4 \pm 1.8$ & $3.7 \pm 0.7$ & $330 \pm 230$ & $70 \pm 20$ & $120 \pm 60$ \\
\hline $\mathrm{K}^{2} / \mathbf{K}_{2}{ }^{d}$ & $36 \pm 10$ & $60 \pm 20$ & $(8 \pm 5) \times 10^{5}$ & $(1.0 \pm 0.5) \times 10^{5}$ & $(2.1 \pm 0.9) \times 10^{5}$ \\
\hline
\end{tabular}

${ }^{a} \mathrm{~N}-\mathrm{H}$ stretching frequencies $\left(\mathrm{v}_{\mathrm{b}}\right.$ : hydrogen bonded; $\mathrm{v}_{\mathrm{f}}$ : free $)$, in $\mathrm{cm}^{-1}$.

${ }^{b}$ Dimerization $\left(\mathrm{K}_{2}\right)$ and multimerization $(\mathrm{K})$ constants, in L.mol ${ }^{-1}$.

Measure of the cooperativity along the supramolecular chain.

${ }^{d}$ Association constant between long oligomers, in L.mol ${ }^{-1}$.

To compare the strength of the association, the best parameter is neither $K_{2}$ nor $K$, but $K^{2} / K_{2}$. Indeed, the association constant between two oligomers $M_{p}$ and $M_{q}(p$ and $q \geq 2)$ is $k(p, q)=$ $\left[\mathrm{M}_{\mathrm{p}+\mathrm{q}}\right] /\left(\left[\mathrm{M}_{\mathrm{p}}\right] .\left[\mathrm{M}_{\mathrm{q}}\right]\right)$. Introducing in this relationship the step by step association constants $\left(\left[\mathrm{M}_{n}\right]=\right.$ $\mathrm{K}_{2} \cdot \mathrm{K}^{\mathrm{n} \cdot 2} \cdot[\mathrm{M}]^{\mathrm{n}}$, for $\mathrm{n} \geq 2$ ) yields $\mathrm{k}(\mathrm{p}, \mathrm{q})=\mathrm{K}^{2} / \mathrm{K}_{2}$, for $\mathrm{p}$ and $\mathrm{q} \geq 2$. Table 1 shows that the association constant between oligomers $\left(\mathrm{K}^{2} / \mathrm{K}_{2}\right)$ is more than 3 orders of magnitude larger for bis-urea EHUT than for mono-ureas. This huge difference is the result of the two levels of cooperativity previously mentioned. The value for EHUT $\left(\mathrm{K}^{2} / \mathrm{K}_{2}=1.0 \times 10^{5} \mathrm{~L} \cdot \mathrm{mol}^{-1}\right)$ can be compared to the 
association constant of a well-known quadruple hydrogen bonded supramolecular polymer based on dimerization of ureidopyrimidone units. For this system in chloroform and at room temperature, values of about $5 \times 10^{7} \mathrm{~L} \cdot \mathrm{mol}^{-1}$ have been reported..$^{18}$ The less strong association of EHUT can possibly be attributed to a lower degree of preorganization, due to the presence of two rotatable covalent bonds in the self-assembling unit.

Furthermore, the knowledge of the association constants makes it possible to compute the whole distribution of oligomers present at a given concentration and thus enhances our understanding of the system. Figure 6a represents the variation of the number average and weight average degrees of polymerization of EHUT versus concentration in chloroform. A useful reference is a virtual compound which would obey the simple isodesmic model, with an association constant equal to the value of $\mathrm{K}^{2} / \mathrm{K}_{2}$ for EHUT: $\mathrm{K}_{n}=1.0 \times 10^{5} \mathrm{~L}_{\mathrm{m}} \mathrm{mol}^{-1}$, for $\mathrm{n} \geq 2$. At high concentrations, EHUT and the reference have the same $\mathrm{DP}_{n}$ and $\mathrm{DP}_{w}$, which is expected, because at high concentrations, the influence of monomers and dimers is negligible. At lower concentrations though, the contrast is striking. The growth of the supramolecular chains is much sharper for EHUT than for the non-cooperative reference. In particular, $\mathrm{DP}_{\mathrm{w}}$ increases from 2 to 100 in a 40-fold concentration increase in the case of EHUT, whereas it takes a 3000-fold increase in the case of the non-cooperative reference. This very sharp transition can be an advantage for applications where switching between polymer-like behavior and monomer-like behavior is desired. A possible drawback is the increased polydispersity of the cooperative system in the region of high chain growth (Figure 6b). The high polydispersity is due to the bimodality of the distribution: a polymer fraction, which has a usual polydispersity of about 2 , is in equilibrium with a relatively high monomer concentration." 

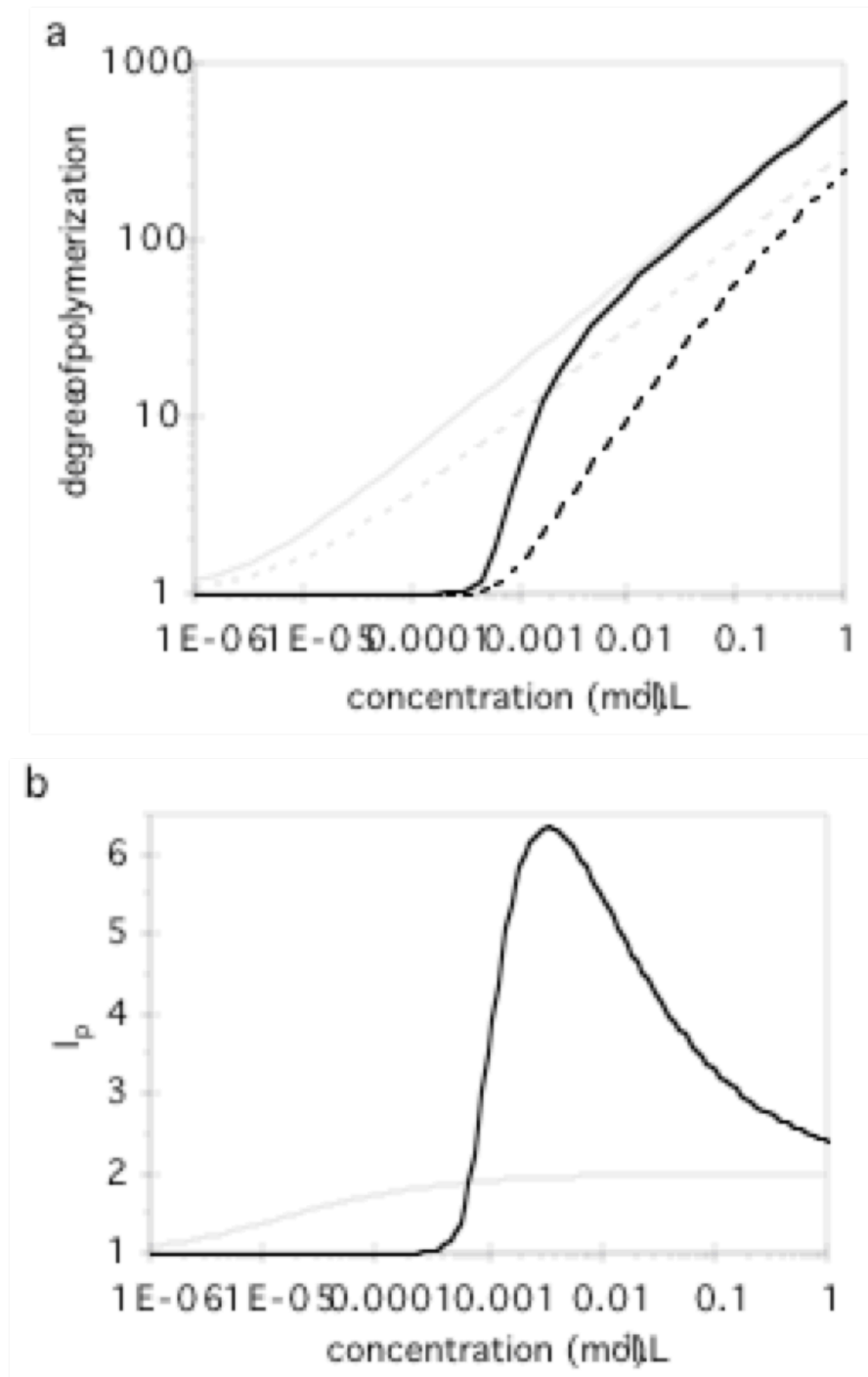

Figure 6. (a) Calculated weight average (full curves) and number average (dotted curves) degrees of polymerization of supramolecular polymers, versus concentration. (b) Calculated polydispersity index of supramolecular polymers, versus concentration. These curves correspond to EHUT ( $\left.\mathrm{K}_{2}=21 \mathrm{~L}^{\mathrm{m}} \mathrm{mol}^{-1}, \mathrm{~K}=1400 \mathrm{~L} \cdot \mathrm{mol}^{-1}\right)$ (bold curves) and an isodesmic reference compound $\left(\mathrm{K}_{2}=\mathrm{K}=1.0 \times 10^{s} \mathrm{~L} \cdot \mathrm{mol}^{-1}\right)$ (plain curves).

2 - Influence of structure: The properties of bis-ureas can be expected to be extremely sensitive to the nature of the bridging group between the two urea functions, because this bridging group is responsible for the first level of cooperativity. Consequently, we synthesized a 
series of bis-ureas having in common the same meta-substituted phenylene core, but either with different side-groups, or with a different position of the methyl group.

Table 2. Solubility of bis-ureas. ${ }^{a}$

\begin{tabular}{llllll}
\hline & DMSO & EtOH & $\mathrm{CHCl}_{3}$ & toluene & heptane \\
\hline PUT & S & S & I & I & I \\
OUT & S & I & I & I & I \\
ODUT & I & I & I & I & I \\
MBUT & S & S & S & I & I \\
EHUT & S & S & S & S & S \\
DMHUT & S & S & S & S $=8 \mathrm{~g} . \mathrm{L}^{-1}$ & S \\
EPUT & S & S & I & I & I \\
PEUT & S & I & I & I & I \\
TBUT & S & I & I & I & I \\
TOUT & S & S & I & I & I \\
2,4/2,6-EHUT & S & I & I & I & I \\
\hline
\end{tabular}

${ }^{a}$ I: insoluble, S: soluble. Solubility was tested at a concentration of $10 \mathrm{~g} . \mathrm{L}^{-1}$ (unless otherwise mentioned) and at room temperature.

2.1 - Influence of the side-groups: Ten different bis-ureas were synthetized by reaction of 2,4toluenediisocyanate with the corresponding amines (Chart 1). None of the three bis-ureas with linear alkyl substituents R (PUT, OUT and ODUT) are soluble in the low polarity solvents tested (Table 2). Introducing branching expectedly improves solubility, because three branched bisureas are soluble in chloroform (MBUT, EHUT and DMHUT) and two of them are even soluble in heptane, at room temperature (EHUT and DMHUT). Branching thus seems to be a necessary 
condition for solubilizing bis-ureas, but it is not a sufficient condition, because EPUT, PEUT, TBUT and TOUT are not soluble in low polarity solvents. It has to be noted that the two most soluble bis-ureas synthesized (EHUT and DMHUT) are in fact mixtures of isomers, obtained from racemic amines.

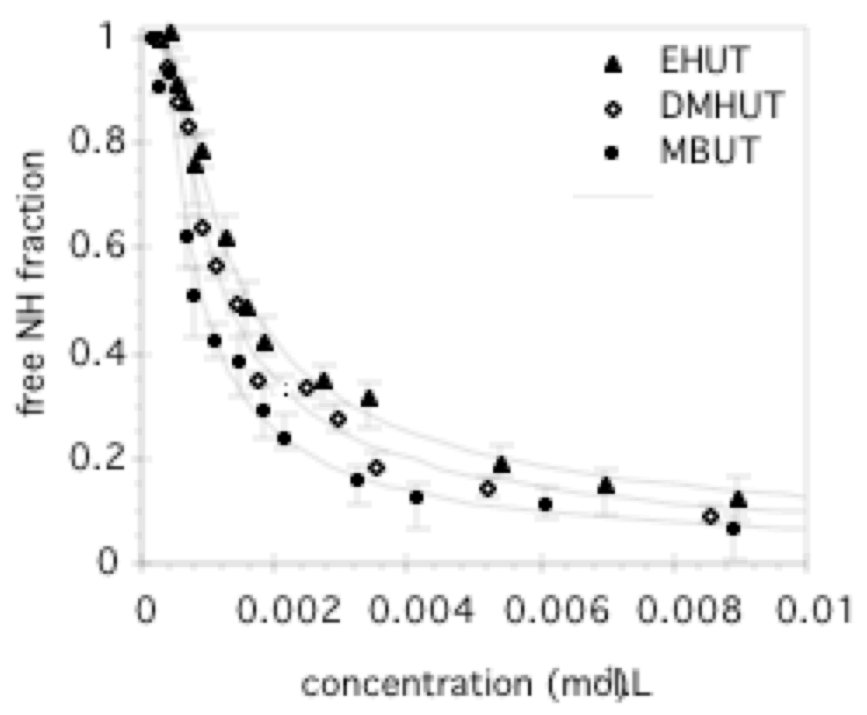

Figure 7. Fraction of free $\mathrm{NH}$ groups of bis-ureas, versus concentration in $\mathrm{CDCl}_{3}$, at room temperature. The curves are calculated with the constants reported in Table 1.

The self-assembling ability of the three chloroform soluble bis-ureas was first evaluated by FTIR spectroscopy. The values of the free N-H fractions (Figure 7) and the association constants derived from them (Table 1) show that the behavior of MBUT, EHUT and DMHUT are very similar. This indicates that the self-assembling mechanism is probably the same for the three compounds. Furthermore, the strength of the association $\left(\mathrm{K}^{2} / \mathrm{K}_{2}\right)$ increases significantly in the order EHUT $\leq$ DMHUT < MBUT. The stronger association of MBUT probably results from a reduced steric hindrance of the 3-methylbutyl substituent compared to the 2-ethylhexyl and 1,5dimethylhexyl groups. A similar trend has been observed in the case of mono-ureas." The 
influence of the structure on the strength of the association is confirmed by the increase in viscosity in the order EHUT < DMHUT < MBUT (Figure 8).



Figure 8. Relative viscosity of bis-ureas, versus concentration in chloroform, at $25^{\circ} \mathrm{C}$.

2.2 - Influence of the position of the methyl group: All the previous bis-ureas described here were synthesized from 2,4-toluene diisocyanate containing less than $4 \%$ of the 2,6 isomer, and were then checked by NMR to contain negligible amounts of the 2,6 bis-urea isomer. The influence of the position of the methyl group was assessed by synthesizing $\mathbf{2 , 4 / 2 , 6 - E H U T ~ f r o m ~}$ the technical mixture of toluene diisocyanate isomers, which contains $80 \%$ of $2,4-$ and $20 \%$ of 2,6- isomers. In fact, the purification by recrystallization changes the proportion, because NMR analysis shows that $\mathbf{2 , 4 / 2 , 6 - E H U T ~ i s ~ a ~ 5 0 / 5 0 ~ m i x t u r e ~ o f ~ t h e ~ t w o ~ b i s - u r e a ~ i s o m e r s . ~ T a b l e ~} 2$ shows that the solubility of $\mathbf{2 , 4 / 2 , 6 - E H U T ~ i s ~ r e m a r k a b l y ~ l o w e r ~ t h a n ~ t h e ~ s o l u b i l i t y ~ o f ~ E H U T . ~}$ Eventhough $\mathbf{2 , 4 / 2 , 6 - E H U T ~ i s ~ n o t ~ a ~ p u r e ~ c o m p o u n d , ~ i t ~ c a n ~ b e ~ c o n c l u d e d ~ t h a t ~ t h e ~ p o s i t i o n ~ o f ~ t h e ~}$ methyl substituent has a very strong influence on the properties of this family of bis-ureas. It is possible that the more symmetrical structure of 2,6-EHUT, compared to 2,4-EHUT, is 
responsible for the formation of a more stable crystalline structure, which would in turn be responsible for a lower solubility.

\section{Conclusion}

Our results provide an unambiguous assignment of the FTIR spectra of solutions of EHUT in the $\mathrm{N}-\mathrm{H}$ region, which makes a quantitative analysis possible. From this analysis, it has been shown that the self-assembly of bis-ureas displays cooperativity at two levels. The first level of cooperativity is due to the synergistic association of the two urea functions of a single molecule. The second level of cooperativity is revealed by the fact that the formation of dimers is less favored than the formation of long oligomers. The consequences of these features are a strong association, a sharp transition between monomer-like and polymer-like properties and a polydispersity larger than 2. Finally, EHUT is not the only compound having such remarkable properties: three bis-ureas with similar behaviors have been identified. This fact paves the way for the rational optimization of the properties of these supramolecular polymers.

\section{Experimental Section}

Viscometry. Solutions were prepared 1 day prior to the measurements and filtered on Millex membranes $(\Phi=0.45 \mu \mathrm{m})$ in the case of chloroform and carbon tetrachloride solutions, but could not be filtered in the case of toluene and dodecane solutions. Dodecane, toluene and carbon tetrachloride were used as received. Chloroform (stabilized with amylenes) was dried over molecular sieves. However, it was checked that the use of this dried $\mathrm{CHCl}_{3}$, or water saturated $\mathrm{CHCl}_{3}$, or $\mathrm{CDCl}_{3}$, yielded the same results within experimental error. Measurements were performed at $25 \pm 0.1^{\circ} \mathrm{C}$ with a Cannon-Manning semi-micro capillary viscometer, except for dodecane solutions, which were characterized with a Low Shear 30 Couette rheometer. 
IR spectroscopy. Infrared spectra were recorded at room temperature on a Nicolet Avatar 320 spectrometer in $\mathrm{KBr}$ cells of 0.05 to $2.5 \mathrm{~cm}$ path length. Solutions in $\mathrm{CDCl}_{3}$ (dried on molecular sieves) were prepared 1 day prior to the measurements. Quantitative data analysis was based on the $\mathrm{N}-\mathrm{H}$ vibration, because the intensity of the $\mathrm{C}=\mathrm{O}$ vibration was not precise enough, due to high solvent absorption at this wavelength. The shape of the free N-H stretching vibration was determined on sufficiently dilute solutions, such that only the free component was detected (reference curve). At higher concentrations, the fraction of free $\mathrm{N}-\mathrm{H}$ groups was deduced from the proportion of the reference curve necessary to remove completely free $\mathrm{N}-\mathrm{H}$ component. Then, the association constants were determined by nonlinear curve fitting, using the following equations (the main source of uncertainty [which is mentioned in Table 1 and Figures 5 and 7] is due to the uncertainty of the deconvolution, because the shape of the hydrogen bonded $\mathrm{N}-\mathrm{H}$ band is ill-defined). In the case of mono-ureas, the fraction of free $\mathrm{N}-\mathrm{H}$ groups, $\mathrm{f}$, is given by Equation (1) ${ }_{14}^{14}$ where $\mathrm{C}_{0}$ is the mono-urea total molar concentration and $\mathrm{C}_{1}$ is the molar concentration of unassociated mono-urea, which is calculated numerically by solving Equation (2) (mass balance equation) $\cdot \cdot^{14}$

$$
\begin{aligned}
& f=\frac{C_{1}}{C_{0}} \cdot\left(1+\frac{K_{2} C_{1}}{1-K C_{1}}\right) \\
& K\left(K-K_{2}\right) C_{1}^{3}+\left(2 K_{2}-2 K-K^{2} C_{0}\right) C_{1}^{2}+\left(1+2 K_{0}\right) C_{1}-C_{0}=0
\end{aligned}
$$

Then, the number-average and weight average degrees of polymerization $\mathrm{DP}_{n}$ and $\mathrm{DP}_{w}$ are computed from Equations (3) and (4).

$$
\begin{aligned}
& \mathrm{DP}_{\mathrm{n}}=\frac{\mathrm{C}_{0}}{\mathrm{C}_{1}} \cdot\left(\frac{1-\left(\mathrm{K}-\mathrm{K}_{2}\right) \mathrm{C}_{1}}{1-\mathrm{KC}_{1}}\right) \\
& \mathrm{DP}_{\mathrm{w}}=\frac{1+\mathrm{KC}_{1}}{1-\mathrm{KC}_{1}}-\frac{2\left(\mathrm{~K}-\mathrm{K}_{2}\right) \mathrm{C}_{1}^{2}}{\mathrm{C}_{0}\left(1-\mathrm{KC}_{1}\right)}
\end{aligned}
$$


In the case of bis-ureas, fibrillar supramolecules are formed, which have been proposed to be either bi- or tri-molecular wires, but not mono-molecular wires. ${ }^{\text {tb }}$ Consequently, Equation (1) does not apply. If the structure is supposed to be bimolecular, then the fraction of free $\mathrm{N}-\mathrm{H}$ groups, $\mathrm{f}$, is given by Equation (5).

$$
f=\frac{C_{1}}{C_{0}} \cdot\left(1-\frac{K_{2} C_{1}}{2}+\frac{2 K_{2} C_{1}}{1-K C_{1}}\right)
$$

Equations (2) to (4) also apply to the bimolecular case.

Proton/deuterium exchange experiments were performed by adding $\mathrm{D}_{2} \mathrm{O}$ to a solution of EHUT in $\mathrm{CHCl}_{3}$. FTIR spectra of the organic phase were recorded in $\mathrm{CaF}_{2}$ cell of $0.1 \mathrm{~cm}$ path length.

Acknowledgement. We thank Nathalie Huet, Karim Laïdi, Frédéric Lortie, and Sylvaine Ragout for their contribution to this project.

Supporting Information Available: Synthesis and characterization of mono-ureas and bisureas.

\section{References}

(1) Zimmerman, N.; Moore, J. S.; Zimmerman, S. C. Chem. Ind. 1998, 604-610.

(2) Supramolecular Polymers; Ciferri, A., Ed.; Marcel Dekker, Inc.: New York, 2000.

(3) Brunsveld, L.; Folmer, B. J. B.; Meijer, E. W.; Sijbesma, R. P. Chem. Rev. 2001, 101, 40714097.

(4) (a) Boileau, S.; Bouteiller, L.; Lauprêtre, F.; Lortie, F. New J. Chem. 2000, 24, 845-848. (b) Lortie, F.; Boileau, S.; Bouteiller, L.; Chassenieux, C.; Demé, B.; Ducouret, G.; Jalabert, M.; Lauprêtre, F.; Terech, P. Langmuir 2002, 18, 7218-7222.

(5) Hanabusa, K.; Shimura, K.; Hirose, K.; Kimura, M.; Shirai, H. Chem. Lett. 1996, 885-886.

(6) (a) van Esch, J.; Kellogg, R. M.; Feringa, B.L. Tetrahedron Lett. 1997, 38, 281-284. (b) van Esch, J.; De Feyter, S.; Kellogg, R.M.; De Schryver, F.; Feringa, B. L. Chem. Eur. J. 1997, 3, 1238-1243. (c) van Esch, J.; Schoonbeek, F.; de Loos, M.; Kooijman, H.; Spek, A.L.; Kellogg, R.M.; Feringa, B. L. Chem. Eur. J. 1999, 5, 937-950. (d) Schoonbeek, F.; van Esch, J.; Wegewijs, B.; Rep, D. B. A.; de Haas, M. P.; Klapwijk, T. M.; Kellogg, R.M.; Feringa, B. L. 
Angew. Chem. Int. Ed. Engl. 1999, 38, 1393-1397. (e) Schoonbeek, F. S.; van Esch, J. H.; Hulst, R.; Kellogg, R.M.; Feringa, B.L. Chem. Eur. J. 2000, 6, 2633-2643. (f) Brinksma, J.; Feringa, B.L.; Kellogg, R. M.; van Esch, J. Langmuir 2000, 16, 9249-9255. (g) de Loos, M.; van Esch, J.; Kellogg, R.M.; Feringa, B. L. Angew. Chem. Int. Ed. Engl. 2001, 40, 613-616. (h) van der Laan, S.; Feringa, B. L.; Kellogg, R. M.; van Esch, J. Langmuir 2002, 18, 7136-7140.

(7) (a) Carr, A. J.; Melendez, R.; Geib, S. J.; Hamilton, A. D. Tetrahedron Lett. 1998, 39, 74477450. (b) Shi, C.; Huang, Z.; Kilic, S.; Xu, J.; Enick, R. M.; Beckman, E. J.; Carr, A. J.; Melendez, R. E.; Hamilton, A. D. Science 1999, 286, 1540-1543. (c) Estroff, L. A.; Hamilton, A. D. Angew. Chem. Int. Ed. Engl. 2000, 39, 3447-3450. (d) Wang, G.; Hamilton, A. D. Chem. Eur. J. 2002, 8, 1954-1961.

(8) Jung, J. H.; Ono, Y.; Shinkai, S. Chem. Eur. J. 2000, 6, 4552-4557.

(9) Moreau, J. J. E.; Vellutini, L.; Wong Chi Man, M.; Bied, C. J. Am. Chem. Soc. 2001, 123, 1509-1510.

(10) Terech, P.; Weiss, R. G. Chem. Rev. 1997, 97, 3133-3159.

(11) Boileau, S.; Bouteiller, L.; Lortie, F. Chem. Eur. J. 2003, 9, 3008-3014.

(12) 'H NMR spectroscopy has not been used, because the N-H vibration bands of EHUT (in these solvents) are extremely broad.

(13) Hvidt, A.; Corett, R. J. Am. Chem. Soc. 1970, 5546-5550.

(14) Jadzyn, J.; Stockhausen, M.; Zywucki, B. J. Phys. Chem. 1987, 91, 754-757.

(15) Oosawa, F.; Kasai, M. J. Mol. Biol. 1962, 4, 10-21.

(16) Martin, R. B. Chem. Rev. 1996, 96, 3043-3064.

(17) In the case of bis-urea EHUT, a more elaborate model ( $\operatorname{Euch}$ as $\mathrm{K}_{2} \neq \mathrm{K}_{3} \neq \mathrm{K}=\mathrm{K}_{\mathrm{n}}$, for $\mathrm{n}>3$ ) could have been anticipated, because the cross section of the supramolecular chains has been proposed to contain two (or three) molecules, ${ }^{4 b}$ which means that the association pattern must be more complex for EHUT than for mono-ureas, which form monomolecular wires. However, the fit to the $\left(\mathrm{K}_{2}, \mathrm{~K}\right)$ model is already very good at the precision of the present measurements (Figure 5 ); it is thus not possible to derive any additional constant. The two constants $\mathrm{K}_{2}$ and $\mathrm{K}$ deduced from the fit must consequently be considered as apparent values of a simple model describing a probably more complex process.

(18) (a) Sijbesma, R. P.; Hirschberg, J. H. K. K.; Söntjens, S. H. M.; Meijer, E. W. Polym. Prep. 1999, 40(2), 1103. (b) Söntjens, S. H. M.; Sijbesma, R. P.; van Genderen, M. H. P.; Meijer, E. W. J. Am. Chem. Soc. 2000, 122, 7487-7493. (c) Sijbesma, R. P.; Meijer, E. W. Chem. Commun. 2003, 5-16. 


\section{Graphic Table of Content}

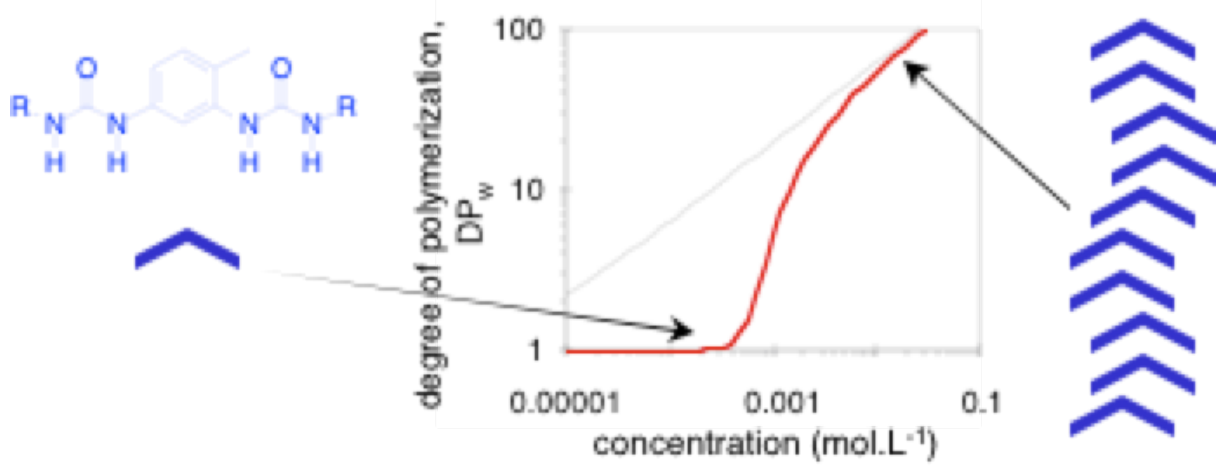

